Egyptian J. Anim. Prod. (2012) 49(2):143-149

\title{
IN VIVO SURVIVAL RATE OF TRANSFERRED ZARIBI GOAT EMBRYOS CRYOPRESERVED BY OPEN PULLED STRAW-VITRIFICATION TECHNIQUE
}

\author{
Sh.M. Shamiah ${ }^{1}$, A.E. Abdel-Khalek ${ }^{2}$, T.A.M. Ashmawy ${ }^{1}$, F.E.El-Keraby ${ }^{1}$ and A. \\ Houssin $^{1}$
}

1- Animal Production Research Institute, Agricultural Research Center, 2- Department of Animal Production, Faculty of Agriculture University of Mansoura

\section{SUMMARY}

The aim of the present study was to examine in vivo survival rate of goat embryos, exposed to vitrification solution or vitrified with OPS, recovered from Zaraibi does (Egyptian local breed) superovulated by PMSG. This research work was carried out at the International Livestock Management Training Center (ILMTC), Sakha, belonging to the Animal Production Research Institute, Agricultural Research Center during the period from March to June 2010. Six non-lactating multiparous goat does were used to examine in vivo and in vitro survival rate of goat embryos, exposed to vitrification solution or vitrified with OPS. All embryos were recovered from Zaraibi does (Egyptian local breed) superovulated by PMSG in the breeding season. Mating was carried out with Zaraibi bucks on the first and second day of estrus. Sex days post-mating the embryos were surgically collected from treated does fasted for $24 \mathrm{~h}$. Before embryo recovery, ovaries of donors were examined by laparoscopy to determine degree of ovarian response to the PMSG. After recovery, embryos at morula and blastocyst stages were exposed to vitrification solution or vitrified with open pulled straws method (OPS). Fresh, vitrified- or exposed-thawed embryos were transferred surgically into uterine horns on day 6 after estrus of synchronized recipients. Results revealed that total superovulatory response /donor was 19.16 in terms of 11.83 CLs and 7.33 unovulated follicles. Ovulation rate was $61.74 \%$ and average number of recovered total embryos/donor was 10.5 in terms of 9.0 transferable embryos and 1.5 unfertilized ova or degenerated embryos, with recovery rates of 88.76 and $85.71 \%$, respectively. Embryo viability was higher for exposed than vitrified embryos in terms of recovery rate (100 vs. $85.7 \%$ ) and survival rate (95.3 vs. 76.2\%). Percentage of pregnant recipients on day 60 of embryo transfer was lower $(P<0.05)$ for vitrified or exposed embryos than fresh embryos $(71.4 \%$ for each vs. $100 \%)$. However, percentage of kidded recipients was higher $(P<0.05)$ for fresh embryos as compared to exposed and vitrified embryos based on total number of recipients (85.7 vs. 57.1 and 42.9\%) or number of pregnant recipients (85.7 vs. 80.0 and 60\%), respectively.

In conclusion, vitrification of Zaraibi goat embryos by OPS technique provided acceptable pregnancy and in vivo embryo survival rates as a method of cryopreservation of caprine embryos.

\section{Keywords: Goats, superovulation, vitrification, open pulled straws, embryo transfer}

\section{INTRODUCTION}

Two exciting developments in goat reproduction are in vivo embryo production or multiovulation embryo transfer (MOET) and in vitro embryo production (IVEP), the technologies for altering or manipulating genetic material to improve the genetic structure of animals. Advanced embryo transfer technique and breeding schemes have led to increase in the offspring from genetically high-grade domestic animals. Embryo cryopreservation is an essential step in any MOET program aimed at improving genetic progress or the embryo transfer industry. Cryopreservation helps to store embryos produced in that program when the number of recipient animals are not sufficient for transfer of the collected fresh embryos. Also, frozen embryos can easily and cheaply be transported from one place to another, without health risks and animal losses (Dobrinsky, 2002 and Guignot et al., 2006).

Vitrification involves the introduction of embryos to high concentration of a cryoprotectant and rapidly cooling by being plunged into liquid nitrogen. This leads to formation of a glasslike solidification, bypassing the possible ice crystal formation during cooling to avoid the crystallization of the extracellular and intracellular contents of the embryos (Kuleshova and Lopata, 2002). Ruminant embryos have been successfully vitrified. It must be borne in mind that exposure of embryos to cryoprotectants with high concentration may lead to toxicity and osmotic damage to the embryo. However, these effects could be reduced via rapid cooling and the selection of the most appropriate cryoprotectant related to its

Issued by The Egyptian Society of Animal Production 
permeability. This could imply that cryoprotectants which are more permeable have a higher risk of toxic damage to the embryo. Consequently, a mixture of low and high permeable cryoprotectants may reduce the osmotic damage (Dattena et al., 2004 and Guignot et al., 2006).

The ability of cryopreservation, thawing, and establishing pregnancies with supernumerary preimplantation embryos has become an important tool in reproduction management in farm animals. The first successful cryopreservation of goat embryos was reported by Bilton and Moore (1976), whereas, the first successful vitrification of goat embryos was reported by Yuswiati and Holtz (1990), though with limited success. Applying the open pulled straw (OPS) vitrification method, developed by Vajta et al. (1997), to goat blastocysts resulted in high embryo survival (64\%) comparable to the best results achieved with conventional slowfreezing in goat embryos (El Gayar and Holtz, 2001). Goat embryos are currently successfully cryopreserved either by using the conventional slow freezing technique, or the vitrification method (Begin et al., 2003 and Guignot et al., 2006). Moreover, goat embryos have generally been successfully vitrified in normal straws, as well as using the latest technique of open pulled straws (OPS) with survival rates following transfer ranging between 9 and 64\% (El-Gayar and Holtz, 2001 and Begin et al., 2003).

In Egypt, no results were reported on survival rate and transfer of embryos vitrified with the open pulled straw (OPS) method in goat. Therefore, the objective of the present study was to examine in vivo and in vitro survival rate of goat embryos, exposed to vitrification solution or vitrified with OPS, recovered from Zaraibi does (Egyptian local breed) superovulated by Equine Corinic Gonadotropin (eCG).

\section{MATERIALS AND METHODS}

This study was carried out at the International Livestock Management Training Center (ILMTC), Sakha, belonging to the Animal Production Research Institute, Agricultural Research Center, Ministry of Agriculture during the period from March to June 2011.

\section{Superovulation treatment:}

Six non-lactating multiparous goat does, taken from herd of Egyptian local breed (Zaraibi goats) raising in Sakha Experimental Station, received hormonal treatment for superovulation in the breeding season. Estrus was synchronized for donor by insertion (Day
0 ) of a vaginal sponge impregnated with $45 \mathrm{mg}$ of Flugestone acetate (FGA, Intervet International B.V. Boxmeer-Holland). The intervaginal sponges were remained for 17 days. One day before FAG-sponge removal doe was injected i.m., with 1000 IU of (eCG) (Foligon, Intervet International BV, Boxmeer, Netherlands). On day of sponge withdrawal, each doe was given a single injection of $0.7 \mathrm{ml}$ (125 mg of $\mathrm{PGF}_{2} \alpha$ (Estromate, Coopers Animal Health LTD, Berkhamsted, England). Each $\mathrm{ml}$ of Estromate contained $263 \mu \mathrm{g}$ of Cloprostenol sodium equivalent to $250 \mu \mathrm{g}$ Cloprostenol.

\section{Embryo recovery:}

Mating was carried out with Zaraibi buck on the first and second day of estrus. Six days post-mating, embryos were surgically collected from treated does fasted for $24 \mathrm{~h}$. Before embryo recovery, ovaries of donors were examined by laparoscopy to determine degree of ovarian response to gonadotrophin treatment.

The day- 6 goat embryos were recovered from the donors under general anaesthesia (Pentothal, Bomac Laboratories, NSW). Each uterine (right or left) horn was flushed by injection of phosphate buffer saline (PBS, $\mathrm{pH}$ 7.2) containing $10 \%$ heat-inactivated $\left(55^{\circ} \mathrm{C}\right.$ for $30 \mathrm{~min}$ ) goat serum (GS) through the fimbrial end of the oviduct and embryos were collected through a Foley catheter (6FG $2.7 \mathrm{~mm}$; Norta, Malaysia) inserted anterior to the body of the uterus. Thus a total volume of 14-20 ml PBS was flushed through each uterine horn. Flashings were collected in sterile plastic Petri dishes for examination under a stereomicroscope. Embryos, which were readily recovered in this manner, were transferred immediately to fresh PBS containing $10 \% \mathrm{GS}$, and incubated in the $37^{\circ} \mathrm{C}$ incubator until transfer, in fresh case to recipients (fresh embryos). Post-incubation, other fresh embryos were exposed to vitrification solution (VS) and transferred to recipients (exposed embryos). In the same line, the recovered embryos were transferred to recipients post-vitrification by open-pulled straw method (vitrified embryos).

To avoid adherences in the abdominal wall, the oviduct and uterine horn were irrigated with abundant heparinized saline solution (1\% $\mathrm{v} / \mathrm{v}$ ) and visible blood clots were removed.

\section{Exposure and vitrification of embryos:}

After recovery, the collected embryos at morula and blastocyst stages were briefly cultured in 50- $\mu 1$ drops of M-199 (Sigma) supplemented with 5\% GS under paraffin oil at $25^{\circ} \mathrm{C}$ in a controlled atmosphere. Vitrification solution (VS) was prepared by supplementing 
(PBS) with 20\% GS, 16.5\% EG (ethylene glycol), 16.5\% dimethyl sulfoxide (DMSO) and $0.5 \mathrm{M}$ sucrose. All recovered embryos were exposed to VS at $25^{\circ} \mathrm{C}$ for 25 seconds without subsequent vitrification (exposed embryos) or were immediately vitrified after exposure (OPS embryos). Open pulled straws (OPS), conventional plastic insemination straws $(0.25 \mathrm{ml}$, IVM L' Aigle, France) were heat-softened over a Bunsen burner and pulled manually. The straws were cooled in air and then cut at the tapering end with a blade. The inner diameter of the tip decreased from 1.7 $\mathrm{mm}$ to $0.8 \mathrm{~mm}$, and the wall thickness diminished from 0.15 to $0.07 \mathrm{~mm}$ according to Vajta et al. (1998). Four embryos were transferred in $50 \mu \mathrm{VS}$ then, transferred to a 3 $\mu 1$ droplet and loaded into the OPS by capillary action. The OPS were plunged immediately into liquid nitrogen $\left(-196^{\circ} \mathrm{C}\right)$.

\section{Thawing of vitrified and dilution of exposed embryos:}

Embryos vitrified in OPS were thawed by placing the narrow end of straw into $25^{\circ} \mathrm{C}$ PBS containing $0.5 \mathrm{M}$ sucrose and $20 \%$ GS for 30 seconds, followed by serial dilutions in $0.25 \mathrm{M}$ sucrose solution for $2 \mathrm{~min}$ and $0.15 \mathrm{M}$ sucrose solution for $5 \mathrm{~min}$ to remove cryoprotectants. Exposed embryos were diluted with the same procedures (Huang et al., 2006).

\section{Embryo Transfer:}

To assess the differences between in vivo survival of embryos as fresh, exposed to vitrification solution or OPS-vitrified, embryos were surgically transferred into uterine horns ipsilateral to the corpus luteum on day 6 after estrus of synchronized recipients using a glass capillary connected to a $1 \mathrm{ml}$ syringe, and does were allowed to carry to term. Volumes of PBS were kept to a minimum of approximately 5-10 $\mu 1$ per transfer. Embryos were transferred within 15 minutes after thawing. Recipients were pluriparous does from the same breed. Estrus in recipients was induced by i.m. injection of $0.004 \mathrm{mg}$ of Buserelin, followed, 7 days later, by i.m. injection of $5.0 \mathrm{mg}$ Dinoprost. Does came in heat were considered suitable recipients. Two embryos at morula and blastocyst stages were transferred 6 days after the end of estrus. Does were deprived of feed for 2 days and of water for 1 day before embryo transfer.

Does were anesthetized by i.v. injection of $1.0 \mathrm{ml}$ Seaxylan ${ }^{\circledR}(20 \mathrm{mg}$ xylazin, WDT, Garbsen, Germany) and $1.0 \mathrm{ml}$ Ursotamin ${ }^{\circledR}$ (0.1 g ketamin, Serumwerke Bernburg, Germany) and placed on a laparoscopy cradle in dorsal recumbence. Embryos were transferred following the technique described by Sohnrey and Holtz (2005).
Pregnancy diagnosis was performed by transrectal ultrasonography (Wolf /8933 / 7 mm-made in U.S.A. with W. German cens system) on day 60 after embryo transfer.

\section{Statistical analysis:}

Data were statistically analyzed with the Chi-square test. The differences were considered to be significant when corresponding P-value was less or equal to 0.05 . All the statistical tests were analyzed by SAS program (SAS, 1999).

\section{RESULTS AND DISCUSSION}

\section{Ovulatory response of superovulated does:}

Results of the superovulatory response of Zaraibi goat does following superovulation using eCG are set out in Table (1). Results showed that average of total ovulatory response/donor was 19.16 in terms of 11.83 corpora lutea (ovulation sites) and 7.33 unovulated follicles and ovulation rate of $61.74 \%$. In addition, average number of recovered total embryos/donor was 10.67 in terms of 9.17 transferable embryos and 1.5 unfertilized ova or degenerated embryos. This reflected in 61.19 and $77.51 \%$ recovery rate of total and transferable embryos, respectively.

The ovulation rate within the MOET technique can be said as superovulation if the donor produced $\geq 3$ ovulations following treatment with gonadotropin (Faruk et al., 2006). In our study, all treated does showed superovulation following eCG with average number of ovulations of 11.8 /donor and ovulation rate of $61.74 \%$. This ovulation rate is satisfactory and comparable to that of other researchers following induction with different levels of eCG and goat breeds (Agrawal 1986; Cameron et al., 1988; Biswas et al., 2000 and Faruk et al., 2006).

The variation in the present results and those reported by several authors could be related to breed differences, PMSG dose or/and FSH and LH ratio within the PMSG used. In this respect, it was observed that prolific breeds response to PMSG more than non-prolific ones. Although the breed difference could be a possible cause, however there could be also variation in $\mathrm{FSH}$ and $\mathrm{LH}$ ratio within the PMSG in different batches and lots of PMSG produced in different laboratory. Increase in $\mathrm{LH}$ ratio compare to FSH could interfere with the ovulation rate in superovulatory process (Fernie et al., 1993).

\section{In vitro survival rate of exposed vs. vitrified embryos:}

Results in Table (2) showed that embryo viability was insignificantly higher for exposed 
than vitrified embryos in terms of recovery rate (100 vs. $85.7 \%)$ and in vitro survival rate (95.3 vs. $76.2 \%$ ). Such effect was expected because exposed embryos were affected by exposure to VS, resulting in loss only in viability not in recovery of embryos. However, vitrified embryos severed from VS and freezing, which resulted in reducing recovery and viability rates of post-vitrified embryos. The present results indicated some lesions on embryo viability when they were exposed to VS and further lesions occurred by OPS vitrification as compared to fresh embryos.

Vitrification involves exposing embryos to high concentrations of cryoprotectants and rapidly cooling by being plunged into liquid nitrogen, leading to formation of a glasslike solidification. This resulted in bypassing the possible ice crystal formation during cooling to avoid the crystallization of the extracellular and intracellular contents of the embryos (Kuleshova and Lopata, 2002). Generally, success of MOET technique depend not only the superovulation rate but also on the embryo recovery rate and quality of embryo (Fernie et al., 1993).

\section{Embryo transfer:}

Results presented in Table (3) showed that percentage of pregnant recipients on day 60 of embryo transfer was significantly $(\mathrm{P}<0.05)$ lower for vitrified than exposed embryos $(71.4 \%$ for each vs. 100\%). However, percentage of kidded recipients was significantly $(\mathrm{P}<0.05)$ the highest for fresh embryos as compared to exposed and vitrified embryos based on total number of recipients ( 85.7 vs. 57.1 and $42.9 \%$ ). The corresponding percentage based on number of pregnant recipients was significantly $(\mathrm{P}<0.05)$ lower for vitrified than fresh and exposed embryos (60 vs. 85.7 and $80.0 \%$ ).

It is of interest to note that the success rate of embryo transfer of Zaraibi goats based on kidded does proportional to total or pregnant recipients was significantly $(\mathrm{P}<0.05)$ higher in exposed versus vitrified embryos. The difference between each type of embryos occurred during the gestation period, indicating incidence of more embryonic mortality at late pregnancy for vitrified than exposed embryos.

Li et al. (1990) recorded a pregnancy rate of $67 \%$ for transferring frozen-thawed hatching and hatched blastocysts, which was lower than that in our study (71.4\%). However, percentages of kidded recipients with OPS embryos obtained in this study were 42.9 and $60 \%$ of embryos, respectively based on total number of recipients and pregnant recipients. These results were lower than others findings as $70 \%$ for embryo survival and the proportion of does kidding was $82 \%$ for goat embryos preserved at blastocyst stage by OPS (AlYacoub, 2009), 64\% for blastocysts cryopreserved with OPS (El-Gayar and Holtz, 2001).

On the other hand, the present kidding rate of goat recipients with OPS vitrification procedure in our study was nearly similar to that obtained by Hong et al. (2007), being from 33 to $51 \%$. These differences were related to marked variation in embryonic stage and type of cryoprotectants used in each study. However, Al-Yacoub (2009) stated that it is hard to distinguish between embryonic stages; and whether morulae had survived during vitrification.

\section{Embryo survival in vivo:}

Results in Table (4) showed that in vivo survival of goat embryos were significantly $(\mathrm{P}<0.05)$ reduced from $71.4 \%$ in fresh embryos to $28.6 \%$ in OPS-vitrified embryos. Such reduction was associated with exposed embryos to VS and further reduction paralleled with freezing process. This means loss of 4 embryos out of $14(28.6 \%)$ as a result of exposing embryos to VS and other 2 embryos out of $14(14.3 \%)$ as compared to fresh embryos. So, the present results indicated the highest loss in survival rate of transferred embryos during exposing process of embryos to VS.

The vitrified technique affected the rate of embryo survival compared to fresh embryos ( 28 vs. $71.4 \%$ ). This result was lower than $64 \%$ as obtained by El-Gayar and Holtz (2001) and $32 \%$ as recorded by Holtz (2005) on OPSvitrified goat embryos. Meanwhile, lower embryo survival (14\%) than that obtained in our study was achieved by Guignot et al. (2006) when goat morulae and blastocysts were vitrified with the OPS method, using 0.4 $\mathrm{M}$ sucrose added to $18 \% \mathrm{EG}$ and $18 \% \mathrm{Me} 2 \mathrm{SO}$ as a vitrification medium.

It is worthy noting that the main difference between exposed and vitrified embryos was in survival rate during pregnancy. Freezing goat embryos may lead to delaying embryonic development and subsequently ova wastage during pregnancy. Guignot et al. (2006) mentioned that OPS technique was not suitable for goat embryo cryopreservation. However, according to the present results and several authors, OPS method for vitrifying caprine morulae and blastocysts is a good alternative method to well-established conventional freezing regimes (Puls-Kleingeld et al., 1992; Nowshari and Holtz, 1995; Baril et al., 2001 and Al-Yacoub, 2009).

The recorded low success rate of goat embryos at both morula and blastocyst stages in term of pregnancy or kidding may be related to the poorest success rate of goat embryos at 
morula stage according to the results of earlier investigations, which indicated marked differences in success rate of goat embryos transferred at the 16-cell (the embryo is referred to as morula), blastocyst and hatched blastocyst stages (Li et al., 1990 and PulsKleingeld et al., 1992). Cryopreservation of morulae by OPS vitrification was ineffectual in terms of pregnancy rate, and embryo survival. However, survival was higher for embryos preserved at blastocyst than hatched blastocyst stages (Al-Yacoub, 2009). Also in goats, morulae have been cryopreserved with unsatisfactory success rates (Puls-Kleingeld et al., 1992), while embryos at blastocyst stage proved to be more suitable for conventional cryopreservation and transfer (Li et al., 1990; Puls-Kleingeld et al., 1992).

The transfer results, however, were discouragingly low, regardless whether exposing embryos to vitrification solution or OPS when vitrification protocols were involved as compared to transfer of fresh embryos. To avoid the reduction in success rate of caprine embryo transfer, embryos recovered as morulae were successfully cryopreserved after in vitro culture to the blastocyst stage (Nowshari and Holtz, 1995). Also, cryopreservation procedures should be taken in mind. This is disappointing, because it implies that there is still an efficient means of cryopreserving embryos without an intact zona pellucida lacking (Al-Yacoub, 2009). The zona pellucida as a protective coat is known to control osmotic pressure (Bronson and McLaren, 1970), transport and diffusion of nutrients and metabolites (Leoni, et al., 2002) and, in all likelihood, also foreign substances including cryoprotectants. The observed reduction in kidding than pregnancy rate for the same type of embryos could be attributed to embryonic loss during pregnancy period because the most accurate test of early pregnancy was ultrasound examination on day 60 post embryo transfer.

In conclusion, the outcome of the present experiment convincingly confirmed that vitrification of Zaraibi goat embryos by OPS technique provided acceptable pregnancy and in vivo embryo survival rates as a method of cryopreservation of caprine embryos. The OPS procedure is suitable for caprine embryo cryopreservation, but not superior to embryos in fresh case. This technique is less elaborate, less time consuming and less costly.

\section{REFERENCES}

Agrawal, K.P., 1986. Hormonal control of ovulation and induction of superovulation in Barbari goats used as donors in embryo transplantation studies. Indian Journal of Animal Reproduction 7: 81-83.

Al-Yacoub, A.N., 2009. Open pulled straw vitrification of Murine and Caprine embryos and timed deep uterine insemination of goats. Ph. D, Faculty of Agricultural Sciences, Georg-AugustUniversity Göttingen, Germany.

Baril, G., A.L. Traldi, Y. Cognie, B., Leboeuf, J.F. Beckers and P. Mermillod, 2001. Successful direct transfer of vitrified sheep embryos. Theriogenology 56:299-305.

Begin, I., B. Bhatia, H. Baldassarre, A. Dinnyes and C.L. Keefer, 2003. Cryopreservation of goat oocytes and in vivo derived 2 - to 4 - cell embryos using the cryoloop (CVL) and solid-surface vitrification (SSV) methods. Theriogenology, 59:1839-1850.

Bilton, R J. and N.W. Moore, 1976. In vitro culture, storage and transfer of goat embryos. Aust. J. Biol. Sci. 29:125.

Biswas, S., B.B. Ghosh, S.K. Bandyopadhyay, M.M. Roy and P.K. Senapati, 2000. Response of Buserelin (GnRH) on synchronization of oestrus and multiovulation in Black Bengal goat treated with PMSG and PGF2 $\alpha$. Journal of Interacademicia 4: 290-293.

Bronson, R.A. and A. McLaren, 1970. Transfer of the mouse oviduct of eggs with and without the zona pellucida. J. Reprod. Fertil. 22:129-37.

Cameron, A.W.N., K.M. Battye and A.O. Trounson, 1988. Time of ovulation in goats (Capra hircus) induced to superovulate with PMSG. J. Reprod. and Fert. 83: 747.

Dattena, M., C. Accardo, S. Pilichi, V. Isachenko, L. Mara, B. Chessa and P. Cappai, 2004. Comparison of different vitrification protocols on viability after transfer of bovine blastocysts in vitro produced and in vivo derived. Theriogenology 62: 481-493.

Dobrinsky, J. R., 2002. Advancements in cryopreservation of domestic animal embryos. Theriogenology 57: 285-302.

El-Gayar, M. and W. Holtz, 2001. Technical note: vitrification of goat embryos by the open pulled-straw method. J. Anim. Sci. 79:2436-2444.

Faruk, O., F.Y. Bari,. M. Shamsuddin, M.G.S. Alam, and M.F. Islam, 2006. Responses of the Black Bengal goat (Capra hircus) to PMSG and surgical embryo recovery within MOET technique. Bangl. J. Vet. Med. 4 (2): 107-115.

Fernie, K., W.S. Dingwall, W.A.C. McKelvey, and J. Fitzsimons, 1993. Superovulation in ewe: The effects of source of gonadotrophin, season, breed and age. 
Proced. British Society of Animal Production. Paper 59.

Guignot, F., A. Bouttier, G. Baril, P. Salvetti, P. Pignon, J.F. Beckers, J.L. Touze, J. Cognie, A.S. Traldi, Y. Cognie, and P. Mermillod, 2006. Improved vitrification method allowing direct transfer of goat embryos. Theriogenology 66: 1004-1011.

Holtz, W., 2005. Recent developments in assisted reproduction in goats. Small Ruminant Res. 60:95-110.

Hong, Q.H., S.J. Tian, S.E. Zhu, J.Z. Feng, C.L. Yan, X.M. Zhao, G.S. Liu, and S.M. Zheng, 2007. Vitrification of Boer goat morulae and early blastocysts by straw and open-pulled straw method. Reprod. Domest. Anim. 42:34-42.

Huang, J.C., H.H.Lin, J.S. Wu, P.H. Tang, D.G. Wang and B.T. Liu, 2006. Vitrification of caprine embryos in microdrops. Symposium COA/INRA Scientific Cooperation in Agriculture, Tainan (Taiwan, R.O.C.), November 7-10.

Kuleshova, L.L. and A. Lopata, 2002. Vitrification can be more favorable than slow cooling. Fertil. Steril. 78, 449-454.

Leoni, G., F. Berlinguer, I. Rosati, and L. Bogliolo, 2002. Resumption of metabolic activity of vitrified/warmed ovine embryos. Mol. Reprod. Dev. 64:207-220.

Li, R., A.W. Cameron, P.A. Batt and A. Q. Trounson, 1990. Maximum survival of frozen goat embryos is attained at the expanded, hatching and hatched blastocyst stages of development. Reprod. Fertil. Dev. $2: 345-350$.
Nowshari, M.A. and W. Holtz, 1995. In vitro culture of goat morulae to blastocysts before freezing. Theriogenology 44:983988.

Puls-Kleingeld M., M.A. Nowshari, and W. Holtz, 1992. Cryopreservation of goat embryos by the one-step or three-step equilibration procedure. In: Lokeshwar RR, editor. Recent advanced in goat production, New Delhi.

SAS, 1999. SAS Institute Inc., SAS Online Doc ${ }^{\circledR}$, Version 8.01, Cary, NC: SAS Institute Inc.

Smith, G.D. and E.A. Silva, 2004. Developmental consequences of cryopreservation of mammalian oocytes and embryos. Reprod. Biomed. Online 9:171-179.

Sohnrey, B. and W. Holtz, 2005. Technical Note: Transcervical deep cornual insemination of goats. J Anim. Sci., 83:1543-1551.

Vajta, G., P. J. Booth, P. Holm, T. Greve and H. Callesen 1997. Successful vitrification of early stage bovine in vitro produced embryos with the open pulled straw method. Cryo-Lett. 18:191-196.

Vajta, G., P. Holm, M. Kuwyama, P. J. Booth, H. Jacobsen, and T. Greve, 1998. Open pulled straw (OPS) vitrification: a new way to reduce cryoinjuries of bovine ova and embryos. Mol. Reprod. Dev. 51:53-61.

Yuswiati, E. and W. Holtz, 1990. Successful transfer of vitrified goat embryos. Theriogenology 34: 629-632.

Table 1. Ovulatory response of superovulated Zaraibi does

\begin{tabular}{lc}
\hline Item & Mean \pm SE \\
\hline Number of superovulated does & 6 \\
Number of corpora lutea/donor & $11.83 \pm 1.40$ \\
Number of unovulated follicles/donor & $7.33 \pm 0.50$ \\
Total ovulatory response/donor & $19.16 \pm 1.30$ \\
Ovulation rate (\%)* & 61.74 \\
Total number of recovered embryos/donor & $10.67 \pm 1.26$ \\
Recovery rate (\%) of total embryos & 91.19 \\
Unfertilized ova or degenerated embryos/donor & $1.5 \pm 0.37$ \\
Number of transferable embryos/donor & $9.17 \pm 0.98$ \\
Recovery rate (\%) of transferable embryos & 77.51 \\
\hline
\end{tabular}

$*$ Ovulation rate $=$ No. of CL $/ \mathrm{CL}+$ unovulated follicles.

Table 2. Recovery and survival rates of Zaraibi goat embryos exposed to vitrification solution or vitrified by OPS method

\begin{tabular}{lccccc}
\hline \multirow{2}{*}{ Type of embryos } & $\begin{array}{c}\text { Number of } \\
\text { Embryos }\end{array}$ & \multicolumn{2}{c}{ Recovered embryos } & \multicolumn{2}{c}{ Viable embryos } \\
\cline { 3 - 6 } & 21 & 21 & 100 & $\mathbf{n}$ & $\mathbf{\%}$ \\
\hline Exposed embryos & 21 & 18 & 85.7 & 20 & 95.3 \\
Vitrified embryos & & & & 16 & 76.2 \\
\hline
\end{tabular}


Table 3. Percentage of pregnant and kidded Zaraibi does received fresh, exposed to vitrification solution or vitrified (OPS) embryos

\begin{tabular}{lcccccc}
\hline \multirow{2}{*}{ Type of embryos } & $\begin{array}{c}\text { Number of } \\
\text { recipients }\end{array}$ & \multicolumn{2}{c}{$\begin{array}{c}\text { Pregnant } \\
\text { recipients }\end{array}$} & \multicolumn{3}{c}{$\begin{array}{c}\text { Kidded } \\
\text { recipients }\end{array}$} \\
\cline { 3 - 7 } & 7 & $\mathbf{N}$ & $\mathbf{\%}$ & $\mathbf{N}$ & $\mathbf{\%}^{(\mathbf{1})}$ & $\mathbf{\%}^{\mathbf{( 2 )}}$ \\
\hline Fresh embryos & 7 & 7 & $100^{\mathrm{a}}$ & 6 & $85.7^{\mathrm{a}}$ & $85.7^{\mathrm{a}}$ \\
Exposed embryos & 7 & 5 & $71.4^{\mathrm{b}}$ & 4 & $57.1^{\mathrm{ab}}$ & $80.0^{\mathrm{a}}$ \\
Vitrified embryos & 7 & 5 & $71.4^{\mathrm{b}}$ & 3 & $42.9^{\mathrm{b}}$ & $60.0^{\mathrm{b}}$ \\
\hline
\end{tabular}

${ }^{\mathrm{a} \text { and } b}$ : Within each column, values with different superscripts are different $\left(\mathrm{P}<0.05, \chi^{2}\right.$ test $)$.

${ }^{(1)}$ : Proportional to total recipients. ${ }^{(2)}$ : Proportional pregnant recipients.

Table 4. In vivo survival and litter size of Zaraibi does received fresh, exposed to vitrification solution or vitrified (OPS) embryos

\begin{tabular}{lcccc}
\hline Type of embryos & $\begin{array}{c}\text { Transferred } \\
\text { embryos (n) }\end{array}$ & $\begin{array}{c}\text { Number of } \\
\text { born kids }\end{array}$ & $\begin{array}{c}\text { In vivo } \\
\text { survival (\%) }\end{array}$ & $\begin{array}{c}\text { Litter } \\
\text { Size/rec. }\end{array}$ \\
\hline Fresh embryos & 14 & 10 & $71.4^{\mathrm{a}}$ & $1.67^{\mathrm{a}}$ \\
Exposed embryos & 14 & 6 & $42.9^{\mathrm{b}}$ & $1.50^{\mathrm{ab}}$ \\
Vitrified embryos & 14 & 4 & $28.6^{\mathrm{c}}$ & $1.33^{\mathrm{b}}$ \\
\hline
\end{tabular}

$$
\text { معدل حيوية أجنة الماعز الزرايبى المجددة بطريقة التزجج في القصيبات المسحوبة و المفتوحة بعد نقلها }
$$

ـ ـ معهج بحوث الاتتاج الحيوانس ، مركز البحوث الزراعية، r ـ قسم انتاج الحبيوان ، كلية الزراعة جامعة المنصورة

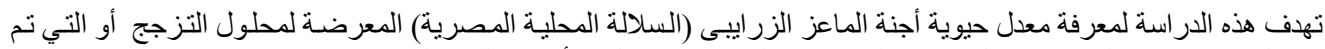

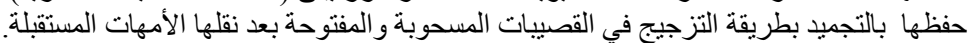

تم عمل تبويض متعدد لستة عنزات متعددة الو لادات وتم عمل تز امن شبقي للماعز وكذللك تم التلقيح الطبيعي بتيس في اليوم الأول التئل

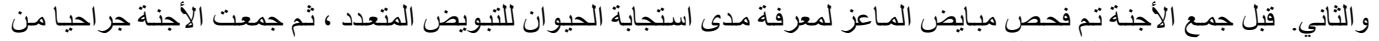

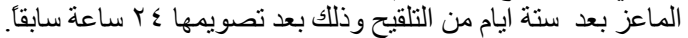

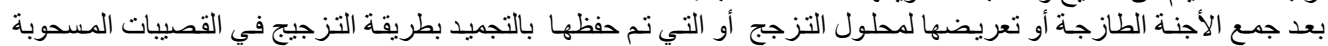

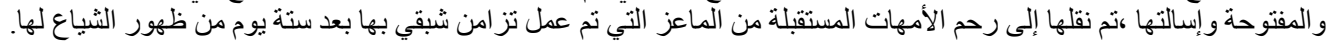

$$
\begin{aligned}
& \text { وكاتت أهم النتائج المتحصل عليها كالتالي: }
\end{aligned}
$$

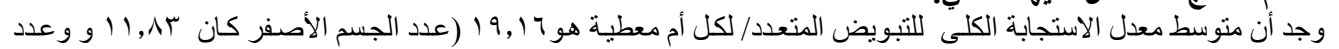

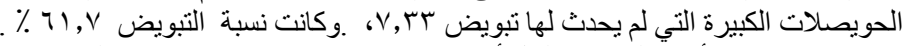

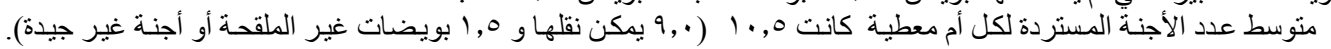

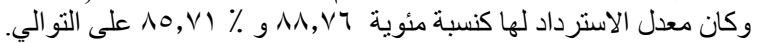

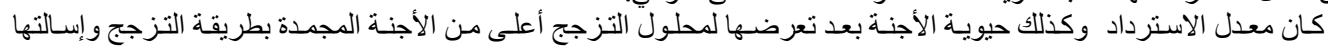

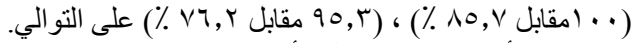

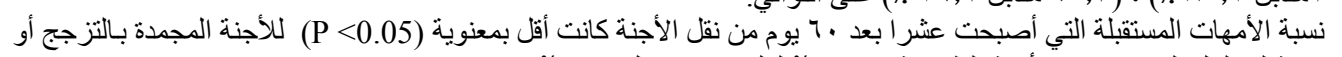

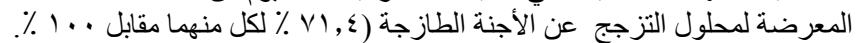

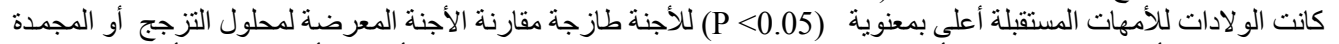

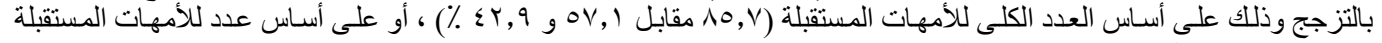

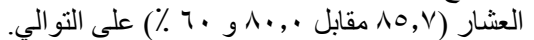

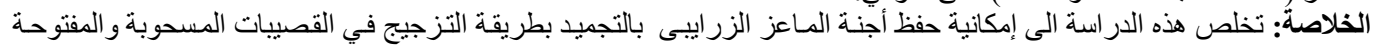

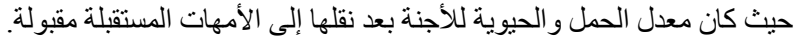

